Article

\title{
Techno-Economic Assessment of Solar Hydrogen Production by Means of Thermo-Chemical Cycles
}

\author{
Massimo Moser ${ }^{1, *}$, Matteo Pecchi ${ }^{1,2}$ and Thomas Fend ${ }^{3}$ \\ 1 Department of Energy System Analysis, Institute of Engineering Thermodynamics, German Aerospace \\ Center (DLR), Pfaffenwaldring 38, 70569 Stuttgart, Germany; matteo.pecchi@natec.unibz.it \\ 2 Faculty of Science and Technology, Free University of Bozen-Bolzano Universitätsplatz-Piazza Università, \\ 5, 39100 Bozen-Bolzano, Italy \\ 3 Department of Solar Chemical Engineering, Institute of Solar Research, German Aerospace Center (DLR), \\ Linder Höhe, 51147 Köln-Porz, Germany; thomas.fend@dlr.de \\ * Correspondence: massimo.moser@dlr.de; Tel.: +49-(0)711-6862-779
}

Received: 20 December 2018; Accepted: 22 January 2019; Published: 23 January 2019

check for updates

\begin{abstract}
This paper presents the system analysis and the techno-economic assessment of selected solar hydrogen production paths based on thermochemical cycles. The analyzed solar technology is Concentrated Solar Power (CSP). Solar energy is used in order to run a two-step thermochemical cycle based on two different red-ox materials, namely nickel-ferrite and cerium dioxide (ceria). Firstly, a flexible mathematical model has been implemented to design and to operate the system. The tool is able to perform annual yield calculations based on hourly meteorological data. Secondly, a sensitivity analysis over key-design and operational techno-economic parameters has been carried out. The main outcomes are presented and critically discussed. The technical comparison of nickel-ferrite and ceria cycles showed that the integration of a large number of reactors can be optimized by considering a suitable time displacement among the activation of the single reactors working in parallel. In addition the comparison demonstrated that ceria achieves higher efficiency than nickel-ferrite (13.4\% instead $6.4 \%$ ), mainly because of the different kinetics. This difference leads to a lower $\mathrm{LCOH}$ for ceria $(13.06 € / \mathrm{kg}$ and $6.68 € / \mathrm{kg}$ in the base case and in the best case scenario, respectively).
\end{abstract}

Keywords: solar hydrogen; concentrated solar power (CSP); two-step thermochemical cycles; simulation; techno-economic assessment

\section{Introduction}

Within the framework of the 2015 United Nations Climate Change Conference (COP 21) in Paris, it has been agreed that global warming should be limited to maximum $2{ }^{\circ} \mathrm{C}$ above pre-industrial levels. In the IEA 450 Policy Scenario, which can be considered as a consistent pathway for the fulfilment of the climate change target, the set limitation for $\mathrm{CO}_{2}$ concentration is $450 \mathrm{ppm}$ [1]. In order to reach this goal, greenhouse gas emissions in 2035 need to be reduced by 30\%, with respect to 2015. Considering the continuous increase of worldwide energy consumption [2], such goal can only be reached by an acceleration in the introduction of renewable energies. However, in such an energy supply system, which is characterized by a high degree of intermittency, some form of storage is required. Among others, conversion of solar energy into chemical fuels such as hydrogen may turn out as an effective form of storage [3], since chemical storage has the key advantage of being free of self-discharge, with respect to thermal and electrical storage systems. Hydrogen can be converted into electricity by means of turbines, generators, and fuel cells, or it can be upgraded to synthetic liquid fuels [4]. 


\subsection{Technology and Literature Review}

Several processes have been considered for the production of solar hydrogen. A comprehensive overview is given in Bozoglan et al. [5]. Five different solar hydrogen techniques can be generally distinguished. One option is to use PV [6], whereas the generated power can be used to run an electrolysis plant [7]. Another option is photoelectrolysis, which consists in the splitting of water in a photoelectrochemical cell powered by solar energy. Despite substantial research effort has been carried out on this topic in the last four decades, substantial problems hinder a wide diffusion of this technology. Solar hydrogen may also be produced by microorganisms such as algae and bacteria (photobiolysis) using solar irradiation as energy source, but this technology is at an early stage of development.

Solar thermolysis has been widely assessed in the past [8]. The feasibility of such a single-step concept is hindered by the high required temperatures (above 2,500 K) as well as by the challenging separation of the produced $\mathrm{H}_{2}$ and $\mathrm{O}_{2}$ gases [9]. Due to these reasons, the techno-economic feasibility of such concept will be low also in the future, according to Kogan [10]. An alternative, as described by Tyner [11], is to use Concentrating Solar Power (CSP) to first generate electrical power, which can be later utilized to run an electrolysis plant. Also a combination of concentrating PV and solar power tower has been recently proposed [12]. Two-step thermochemical cycles offer two key advantages in comparison to direct solar thermolysis $[13,14]$ : first, the gas separation is realized by the absorption of the oxygen into the reactor material, while pure hydrogen is released. Second, the required temperature is significantly lower than for thermolysis. In addition, thermodynamic analysis shows that some of those cycles can achieve-in principle - efficiencies up to 70\%, if energy recovery is applied [15].

Several materials have been analyzed both theoretically and experimentally [16]. Among them are zinc, iron, tin, terbium oxides, mixed ferrite, ceria, and perovskite [17]. Cycles based on nonvolatile metals have clear advantages in comparison to sulfur- and bromine-based cycles, in terms of toxicity and corrosivity. In addition, differently from volatile metal oxide-based processes, these materials allow the construction of fixed-bed structural reactors (monoliths) with important structural strength. Among this group mixed ferrites offer the advantage of relatively low reaction temperatures and therefore they have been widely investigated. nickel-ferrite cycles belong to the more general mixed-metal ferrite cycles, whose general reactions are shown in Figure 1. [18].

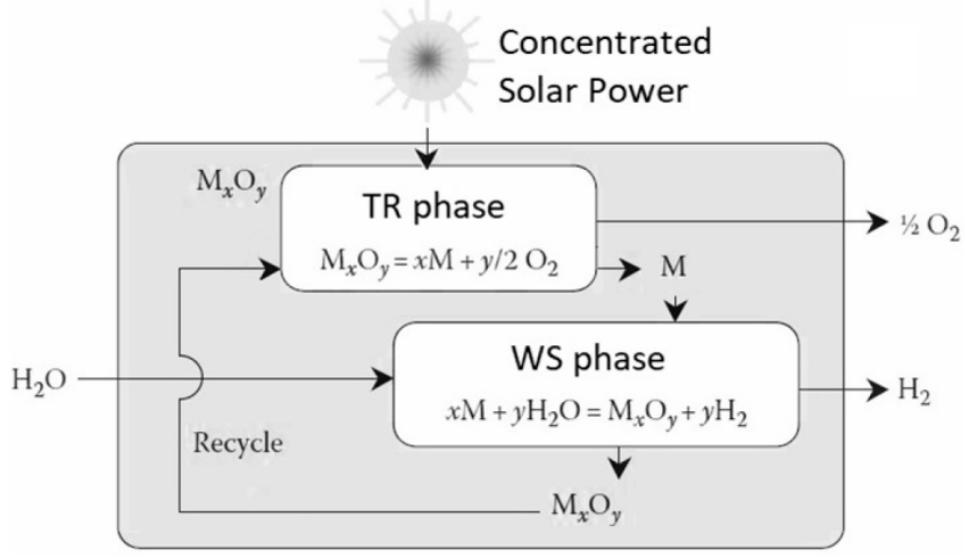

Figure 1. Basic scheme of a 2-step metal-oxide thermochemical process [18].

The first reaction is the endothermic thermal reduction step (TR), in which the metal oxide is reduced by removing part of the oxygen contained in it. The parameter $\delta$ is the non-stoichiometric factor that indicates to which extent the reaction occurs. Such non-stoichiometric factor is a function of process temperature and oxygen partial pressure [19]. In the second step—the exothermic water splitting (WS) - the MO is oxidized with water while hydrogen is released. Recently, an industrial-scale plant $\left(750 \mathrm{kWh}_{\text {th }}\right.$ ) which uses concentrated solar radiation to split water into hydrogen and oxygen using nickel ferrite has been realized at the Plataforma Solar de Almeria (Almeria, Spain) and is 
expected to produce $3 \mathrm{~kg}$ of hydrogen per week [20]. Within those systems, two or more reactors are used in parallel to perform the batch-processes achieving a quasi-continuous hydrogen production. The main drawbacks of this system are material sintering and a relatively low efficiency.

Within the last years, ceria has become the benchmark for non-volatile metal oxide systems. The use of ceria as an interesting material for solar hydrogen applications has risen due to its quick kinetics and its structural stability over a wide range of temperatures [21]. However, higher temperatures with respect to nickel-ferrite, are required in order to achieve satisfying values of the non-stoichiometric factor. In addition, ceria-based cycles simultaneously produce a mixture of hydrogen and carbon monoxide, with the option to further process the syngas in a Fischer-Tropsch reactor to produce liquid solar fuels [22,23]. For those reasons this work focuses on the evaluation of nickel-ferrite and ceria and compares the resulting figures with hydrogen generated by water electrolysis.

With regard to the economic evaluation of hydrogen production by means of solar thermochemical cycles, few studies exist. Graf et al. [24] presented a simplified techno-economic characterization of hybrid-sulfur cycles and a metal oxide based cycles. The calculated price for thermochemical cycles ranged from $3.5 € / \mathrm{kg}$ to $12.8 € / \mathrm{kg}$ in an optimistic and conservative scenario, respectively. Recently, Nicodemus compared again solar thermochemical cycles and solar PV electrolysis [25]. The focus was on the learning curves for each of the main plant components. In that paper, hydrogen production costs of two main routes were presented, i.e., via PV-electrolysis and via solar thermochemical cycles $(\mathrm{Zn} / \mathrm{ZnO})$. Depending on the assumptions regarding different policy support mechanisms, the expected $\mathrm{LCOH}$ for the solar thermochemical cycle were in the range between $4 € / \mathrm{kg}$ and $4.5 € / \mathrm{kg}$. The paper further highlighted that the cost projections for PV and electrolysis may lead to a $\mathrm{LCOH}$ of $2 € / \mathrm{kg}$ and $3 € / \mathrm{kg}$, calling for incentive-based policy also for thermochemical cycles in order to improve their long-term economic competitiveness.

\subsection{Intention}

The aim of the presented work has been the development of a flexible model for the preliminary assessment and the comparison of different two-step thermochemical cycles for solar hydrogen production, taking into account at the same time technical and economic aspects. We believe that the development of such a simplified model is relevant in order to identify key techno-economic performance parameters of such processes, and can improve the understanding over differences and similarities of different concepts and plant configurations. In addition, the produced results may be useful in order to highlight some promising paths for future research work. Indeed, the main novelty of this work consists in bridging the gap between in-depth technical studies and economic analyses. First ones typically focus on very specific technical aspects such as new materials or component design and do not include economic analysis [20-22]. In the second ones, which to the best of our knowledge assume fixed or reference plant configurations, the inter-dependence between economic input parameters and optimal plant design are neglected [24,25].

The model developed within the framework of this study allows designing an optimal number of modules per reactor for large-scale applications as a function of several technical constraints. In fact, if only one reactor would be used, a large amount of the available solar energy would be wasted. This happens since the solar field power output must be sized to fulfil the peak power demand of the reactor, but a single reactor absorbs its peak power value only for a small fraction of the cycle. A constant power requirement makes a more efficient use of the available solar power. This ideal behavior can be at least approached by running several reactors together in a module, each reactor starting its cycle with a given time displacement. The optimal number of reactors per module allows approaching a constant value for the module power consumption curve.

Moreover, the objective is the analysis of long-term cost perspectives and the comparison of solar thermochemical cycles based on CSP with alternative renewable hydrogen production routes. 
In order to achieve this goal, a simplified model has been developed based on available literature and in cooperation with the DLR Institute of Solar Research.

The paper is structured as follows: after a literature review, the structure and the details of the technical model are described and discussed. A dedicated technical model has been realized for each of the plant components, i.e., solar field, single reactor, reactor groups. A distinction has been done between the materials used in the reactors. In particular, physical properties and kinetics of both nickel-ferrite and ceria have been considered based on available literature. A simplified economic model has also been implemented. Finally, a case study has been carried out. Technical and economic performances are presented and critically discussed. The technical comparison takes into account the two mentioned reactor materials. The economic analysis includes the consideration of different scenarios and takes into account learning curves for CSP. The hydrogen production cost obtained via solar thermochemical cycles are compared with those for competing systems such as electrolysis powered by photovoltaics (PV).

\section{Materials and Methods}

The model consists of following submodules:

- Sun power evaluation model

- Reactor model

- Kinetic models for Nickel-Ferrite and Ceria

- Plant model

- Economic model

The paper first presents the structure of the developed model. In the subsequent analysis the results of the parametric studies are shown and critically discussed. Finally, key findings and suggestions for future research activities are summarized in the conclusions and in the outlook, respectively.

\subsection{Technical Model}

As mentioned above, the technical model consists of four sub-models implemented in the Python programming language, which are described in the following sections. The description focuses on the overall structure of the models. Details about single components and validation of the numerical results relative to them can be found in the available literature, which has been taken as a basis for the model development. However, at the plant scale, no validation is available.

\subsubsection{Sun Power Evaluation Model}

The first step of the calculation evaluates the available solar power. In a CSP plant for hydrogen production (Figure 2), the incoming irradiation is reflected by the heliostat field and concentrates onto the top of a tower, where a receiver is located. Since both the current available direct normal irradiance (DNI) on the solar field and the position of the sun continuously change over the day and over the seasons, an accurate evaluation of the net usable solar power is of foremost importance.

The calculation procedure is performed according to these steps:

- Available DNI data (hourly time step for a typical meteorological year) are read from a file

- The position of the sun at each time step is calculated according to [26]. The results from this step are the solar elevation angle and the solar azimuth angle

- Given the sun position, the geographical location of the plant, the receiver capacity and the tower height, the current efficiency of the solar field $\eta_{s f}$, namely the ratio of available DNI that is directed towards the receiver, can be calculated from an efficiency matrix [27]. The interpolation among matrix points is linear. The details of the interpolation procedure of the 5-D matrix can be found in [28]. The matrix takes into account different loss mechanisms, due to the reflection of the 
solar radiation towards the receiver (i.e., geometrical losses such as cosine losses, shading and blocking), and to the non-ideal behavior of the heliostats (i.e., astigmatism).

- Finally, the net available heat at the receiver is assessed as [20]:

$$
\dot{Q}_{s f}=D N I \cdot \eta_{s f} \cdot A_{s f} \cdot\left(1-f_{\text {spill }}\right)
$$

where $Q_{s f}$ is further reduced by a non-dimensional spillage factor $f_{\text {spill }}$, as not all irradiation reflected by the heliostats hits the receiver [29].

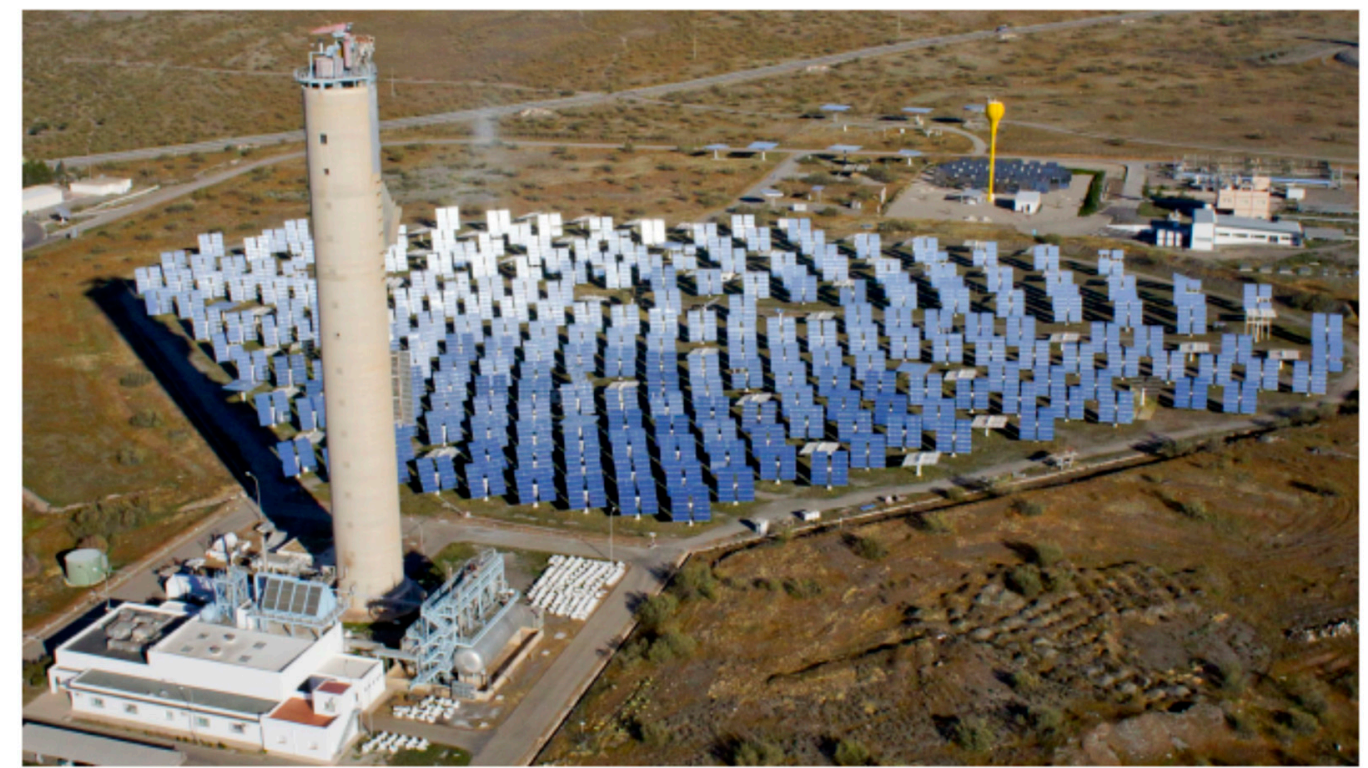

Figure 2. CSP heliostat field and solar tower at the Plataforma Solar de Almería, Spain (DLR).

\subsubsection{Single Reactor Model}

The thermodynamic model for a single reactor is based on [20], which is a simplified 0-D model with energy balances on absorber and window surfaces. The main heat fluxes in and from the receiver are shown in Figure 3.

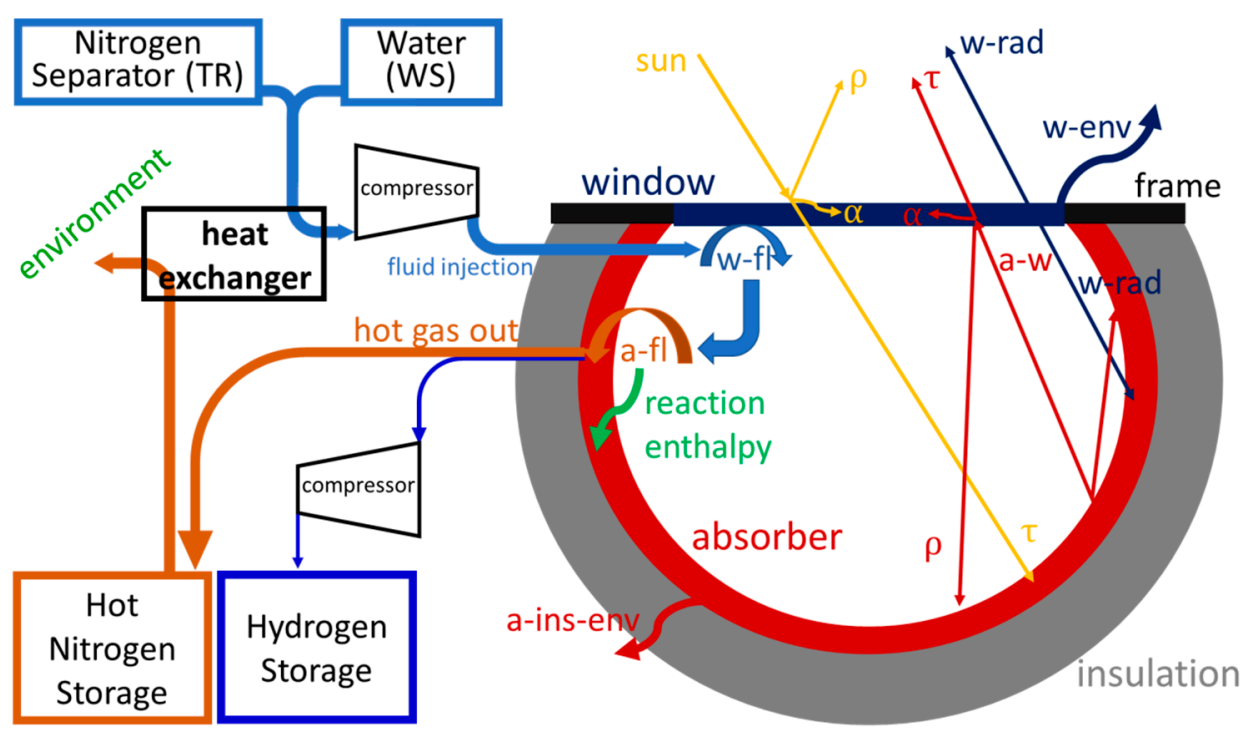

Figure 3. Thermodynamic solar reactor model, based on [20] with own adaptations. 
The reactor is composed of the absorber, i.e., the metal oxide active material, and of a quartz window. In reality, the absorber is bell-shaped, however, in the model this form is approximated as a half-sphere in order to simplify the calculations. In addition, the absorber is assumed to behave as a black-body.

The available solar power (straight yellow arrow) hits the quartz window and is either reflected, absorbed or transmitted toward the absorber. The absorber reflects towards the window (straight red arrow), and also in this case the radiation is either absorbed, transmitted or reflected by the window. The absorber also loses a share of power through the insulation (curly red arrow). Also the quartz window itself loses heat by radiation and convection to the environment (straight and curly dark blue arrows). During the thermal reduction phase, nitrogen is pre-heated and injected while the absorber temperature is kept constant. The nitrogen flows through the absorber pores with an initial temperature lower than the one of the absorber, and reaches thermal equilibrium with it. The heat absorbed from the absorber to heat up the nitrogen is simply calculated knowing the gas specific heat. As nitrogen flows through the active material, this latter releases oxygen. During the water splitting phase steam is injected instead of nitrogen, while hydrogen is released, but the modelling approach is the same. The details of the calculation of each single term in the heat fluxes can be found in [20].

Nitrogen is obtained by air separation in a nitrogen generator consuming electricity, while the electricity consumption for its pumping in the system is calculated based on a fixed pressure ratio.

A heat exchanger between nitrogen and steam inlet and outlet flows fulfils the overall heat requirements (boiling and overheating). When hot nitrogen exits from the reactor, it is stored in a container with a certain thermal efficiency. This operation is not performed with water and hydrogen exiting the reactor. Whenever heat is required to heat up nitrogen or to vaporize and over heat steam, the required amount is subtracted from the value available in the storage, also in this case considering a certain efficiency to simulate the losses.

The heat balance on the absorber and on the quartz window are performed at each time step by applying a forward Euler method. The energy balance on the absorber is:

$$
\frac{d T_{a}}{d t}=\frac{\dot{Q}_{s u n, \tau}+0.5 \cdot \dot{Q}_{w, r a d}-\dot{Q}_{a-w, r a d}-\dot{Q}_{a-i n s, \text { cond }}-\dot{Q}_{a-f l, c o n v}-\dot{Q}_{h, \text { reac }}}{m_{a b s} \cdot c_{p, a b s}}
$$

The energy balance on the window is:

$$
\frac{d T_{w}}{d t}=\frac{\dot{Q}_{s u n, \alpha}-\dot{Q}_{w, r a d}+\dot{Q}_{a-w, \alpha}-\dot{Q}_{w-f l, c o n v}-\dot{Q}_{w-e n v, c o n v}}{m_{w} \cdot c_{p, w}}
$$

\subsubsection{Kinetic Models for Nickel-Ferrite and Ceria}

The duration of each reaction phase (TR and WS) is determined by the kinetics. For nickel-ferrite a unimolecular decay law has been used as proposed by [19], based on [30]. The non-stoichiometric factor $\delta$ can be calculated linearly interpolating the results of [19] for the reaction temperature $\left(1400^{\circ} \mathrm{C}\right.$ for the TR phase) and the oxygen partial pressure $\left(10^{-5}\right.$ bar $)$.

From $\delta$, the maximum value of the oxygen moles that can be extracted at equilibrium $\psi_{\mathrm{O}_{2} \text {, max }}$ can be assessed, considering the mass and the molar mass of the absorber:

$$
\psi_{O_{2}, \max }=\frac{\delta \cdot m_{a}}{2 \cdot M M_{a}}
$$

After that, the oxygen release at each time step can be assessed by integration of the kinetic differential equation:

$$
\frac{d \psi_{\mathrm{O}_{2}}}{d t}=-k_{\text {reg }} \cdot \psi_{\mathrm{O}_{2}}
$$


So it possible to compute the moles of oxygen released up to a certain instant $n_{\mathrm{O}_{2}}(t)$ by integration, and to obtain the molar production rate $\dot{n}_{\mathrm{O}_{2}}(t)$ as the difference of the value of $n_{\mathrm{O}_{2}}(t)$ in two consecutive time steps:

$$
\dot{n}_{\mathrm{O}_{2}}(t)=\frac{n_{\mathrm{O}_{2}}(t)-n_{\mathrm{O}_{2}}(t-1)}{\delta t}=\frac{\psi_{\mathrm{O}_{2}, \max }}{\delta t} \cdot\left(e^{-k_{\text {reg }} \cdot(t-1)}-e^{-k_{\text {reg }} \cdot(t)}\right)
$$

For the WS phase, a similar procedure applies, but also the steam concentration is accounted for in the differential equation:

$$
\frac{d \psi_{\mathrm{O}_{2}}}{d t}=-k_{w s} \cdot c_{\mathrm{H}_{2} \mathrm{O}} \cdot\left(\psi_{\mathrm{O}_{2}, \max }-\psi_{\mathrm{O}_{2}}\right)
$$

The integration follows the same procedure as for the TR phase. The enthalpy of reaction associated to the oxygen release and to the oxygen absorption are considered fixed values and have been taken from [31], while the specific heat capacity of the ferrite have been taken from [32].

For ceria the kinetic calculation is similar, with the only difference that in this case oxygen can be released also during the transition phase between WS and TR. The value of $\delta$ is given in [33] as a function of the temperature and of the oxygen partial pressure, while the constants $k_{r e g}$ and $k_{w s}$ has been interpolated from [34]. The enthalpy of reaction for the regeneration phase is not constant, as suggested by [33], while the enthalpy of oxygen absorption has been considered equal to the nickel-ferrite case, since no data was available in the literature.

\subsubsection{Plant Model}

Due to the fact that the temperature requirements for the two phases of the cycle are different-i.e., for nickel-ferrite $1400{ }^{\circ} \mathrm{C}$ and $900^{\circ} \mathrm{C}$ for TR and WS, respectively-the power needed by each single reactor strongly varies over time, as shown in Figure 4 (left). The power requirement is the highest during the transition from WS to TR phase, when a heat-up takes place. During the TR phase the temperature of the absorber remains constant, while the power requirement falls to an intermediate value. The power requirement of the TR phase is not constant due to the impact of the reaction kinetics on the thermal balance. After that a cool down takes place. During this phase the power requirement falls to zero. The last phase is the WS, when the power requirement slightly increases.
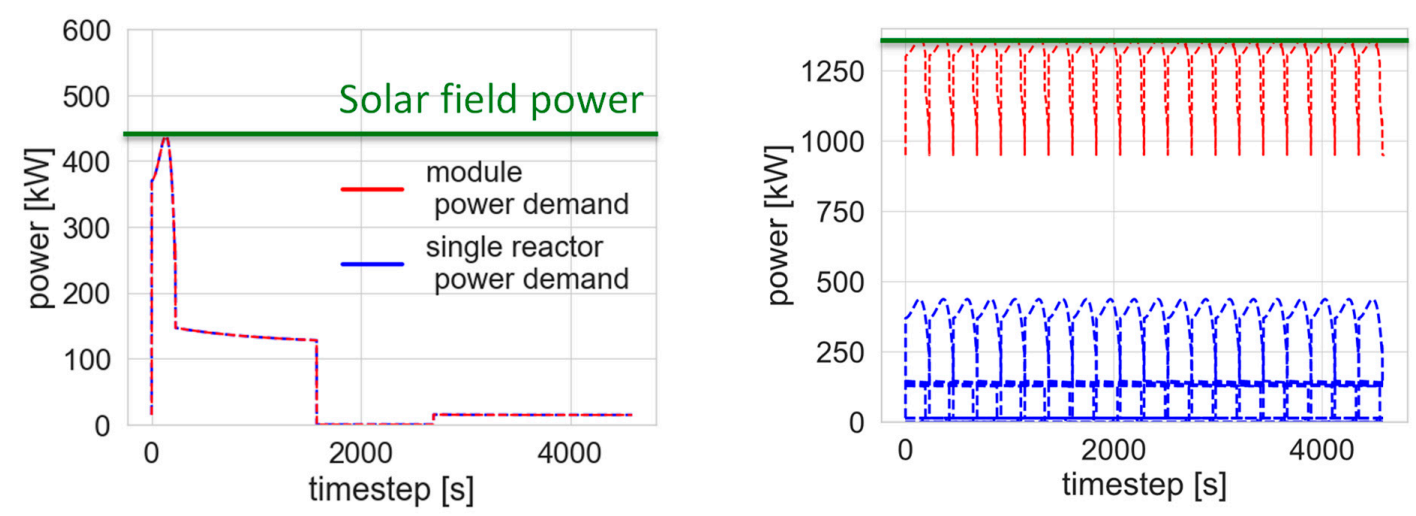

Figure 4. Heat requirement of a single nickel-ferrite reactor (left), and of a module (right) during a complete cycle.

If only one reactor is used, a large amount of the available solar energy (i.e., the difference between the peak power and the current value of the required power) would be wasted, since the solar field would need to be sized on the peak of the reactor power curve. A constant power requirement makes a more efficient use of the available solar power, (red line in Figure 4). This ideal behavior can be at least approached by running several reactors together in a module, each reactor starting is cycle with a given time displacement (Figure 4, right plot). The solar power consumption of a module is then the 
sum of the power consumption of its single reactors, considering the time displacement of each reactor power curve. The optimal number of reactors per module allows approaching a constant value for the module consumption curve. It is a function of the duration of the heat-up phase, which in turn is a function of the chosen absorber material. Finally, a complete plant consists of a series of modules, and in each hour of the year, the number of activated modules in the plant depends on the currently available sun power. The main results of the technical model are-for each time step-temperature value of absorber and quartz window, heat flows and solar heat requirements for a single reactor as well as for an entire module, oxygen and hydrogen production rates. In the end, the size of the main plant components is evaluated.

\subsection{Economic Model}

The results of the technical model are fed into the economic model in order to calculate the levelized cost of hydrogen ( $\mathrm{LCOH})$. The $\mathrm{LCOH}$ is defined as the ratio between the total annual cost and the amount of produced hydrogen, considering the energy cost for hydrogen pumping in the long-term storage:

$$
L C O H=\frac{\text { total annual cost }}{m_{H_{2}, \text { annual production }}}
$$

The total annual cost is calculated as a sum of a series of items. The most important one is the annual instalment [Mio. $€ / y$ ], which is assumed to be completely covered by the loan, according to:

$$
\text { inst }_{\text {ann }}=i n v \cdot \frac{i \cdot(1+i)^{\left(t_{\text {debt }}-t_{\text {construction }}\right)}}{(1+i)^{\left(t_{\text {debt }}-t_{\text {construction }}\right)-1}}
$$

Another cost item is the metal oxide substitution, as it is assumed that the active material is prone to deterioration and only can withstand a certain number of cycles before being substituted. Annual cost of water, technical nitrogen, nitrogen compression and a general factor for operation and maintenance and insurance are taken into account. The main assumptions used for the calculation of such cost are listed in Table 1.

Table 1. Assumption of main assumptions for the economic model (base case).

\begin{tabular}{lcc}
\hline \multicolumn{1}{c}{ Parameter } & Unit & Value \\
\hline Construction time & $\mathrm{y}$ & 2 \\
Debt period & $\mathrm{y}$ & 20 \\
Plant lifetime & $\mathrm{y}$ & 30 \\
Interest rate & $\% / \mathrm{y}$ & 0.08 \\
Discount rate & $\% / \mathrm{y}$ & 0.05 \\
Absorber life & $\mathrm{y}$ & 1 \\
Absorber specific cost & $€ / \mathrm{kg}$ & 10 \\
Water use for mirror cleaning & $\mathrm{m}^{3} / \mathrm{m}^{2}$ & 0.02 \\
Water cost & $€ / \mathrm{m}^{3}$ & 3 \\
$\mathrm{~N}_{2}$ pumping consumption & $\mathrm{kWh} / \mathrm{mol}^{2}$ & 0.001356 \\
Pressure ratio & - & 5 \\
Adiabatic compressor efficiency & - & 0.7 \\
Cost of electricity & $€ / \mathrm{kWh}$ & 0.20 \\
O\&M cost & $\% \mathrm{inv} / \mathrm{y}$ & 2 \\
Insurance factor & $\%$ inv $/ \mathrm{y}$ & 0.5 \\
\hline
\end{tabular}

The total investment inv is the sum of the investment for all plant components, i.e., heliostat field, thermal storage for nitrogen, hydrogen underground storage, reactor and solar tower. Some important data and the main cost assumptions for the base case are reported in Table 2. Also the hydrogen efficiency storage is reported, which considers a loss of $10 \%$ of the energy content in the gas for its pumping and extraction in the storage $[35,36]$. 
Table 2. Investment assumptions (base case).

\begin{tabular}{lcc}
\hline \multicolumn{1}{c}{ Parameter } & Unit & Value \\
\hline Solar field specific investment & $€ / \mathrm{m}^{2}$ & 150 \\
Thermal storage specific investment & $€ / \mathrm{kWh}_{\text {th }}$ & 30 \\
Hydrogen storage specific investment & $€ / \mathrm{kWh}_{\text {th }}$ & 30 \\
Hydrogen storage efficiency & $\%$ & 90 \\
Reactor shell cost & $€ / \mathrm{piece}$ & 5000 \\
Specific cost of insulation & $€ / \mathrm{m}$ & 10,000 \\
Specific cost of absorber & $€ / \mathrm{kg}$ & 10 \\
Absorber mass & $\mathrm{Kg}$ & $150-250$ \\
Reactor total mass & $\mathrm{kg}$ & 700 \\
\hline
\end{tabular}

The tower specifications (e.g., tower height as a function of receiver capacity) required for the cost calculation is based on [27]. The total reactor mass is based on internal consideration at DLR, and is supposed to be fixed for simplicity reasons. The volume available for the absorber is also fixed, since it depends on the reactor configuration based on [20]. The absorber mass depends on the density and porosity of the material, however, due to the small fraction of reactor mass in the absorber material, the total mass of the reactor is not a function of it, but it is fixed. The absorber specific cost refers to an eventual industrial scale production, and is the same for the two materials.

\section{Results and Discussion}

\section{Case Study}

The developed model is finally used to assess the $\mathrm{LCOH}$ in a case study. The selected site for the analysis is the Plataforma Solar de Almería (Almeria, Spain). Figure 5 shows a DNI distribution map of Spain. One can observe that South-East Spain is characterized by highest annual DNI values (around $2100 \mathrm{kWh} / \mathrm{m}^{2} / \mathrm{y}$ ). The plant is assumed to have a heliostat field with 3000 heliostats with each $40.96 \mathrm{~m}^{2}$ surface. The nominal receiver thermal power is of $90 \mathrm{MW}$.

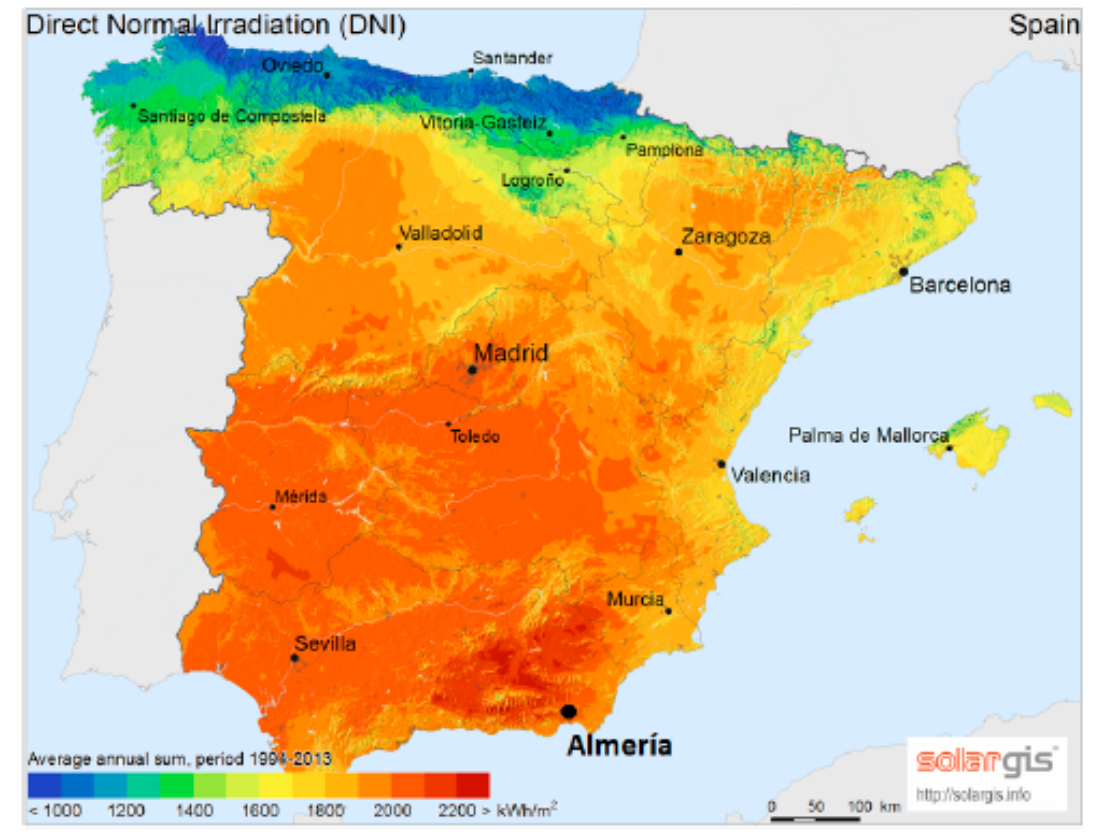

Figure 5. DNI distribution map of Spain [37].

First, key technical plant characteristics such as optimal reactor number for a module, overall energy balances and typical production profiles are shown. A comparison between Nickel-Ferrite and 
Ceria is carried out. Second, the economic results for the base case are presented and a sensitivity analysis on selected parameters is carried out. Finally, a best case scenario is evaluated and its results are reported.

A view on the energy balance for a single reactor helps understanding the main loss mechanisms of such systems. A Sankey plot for a full reactor cycle is shown in Figure 6, which represents the time integral of the power fluxes during the whole cycle. The enthalpy term is related to the efficiency. The resulting reactor efficiency in the base case is $6.4 \%$ for nickel-ferrite and $13.4 \%$ for ceria. Such a difference is mainly due to the faster kinetics of ceria, which leads to a shorter cycle duration time. In both cases, the re-radiation losses through the window are very high and accounts for $59.4 \%-67.0 \%$ of the incoming solar energy. The geometry of the absorber and of the window has been taken as a given input and has not been optimized within the framework of this work.

\section{Nickel-Ferrite}

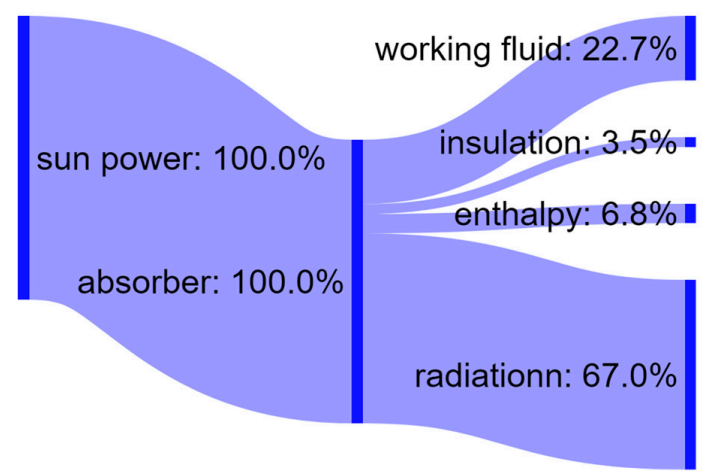

\section{Ceria}

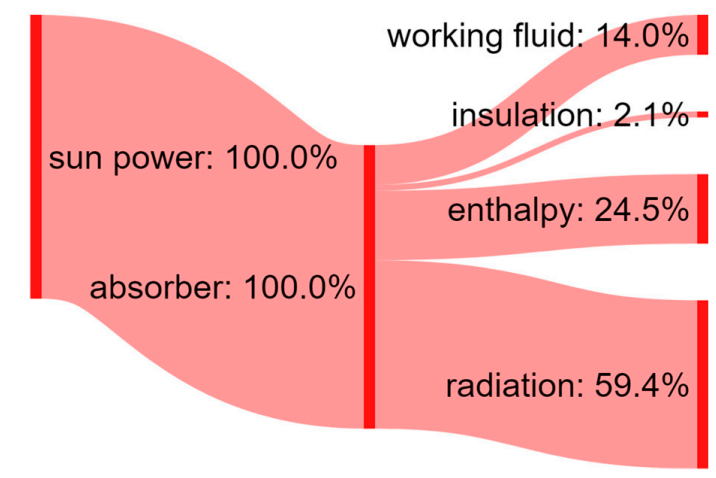

Figure 6. Sankey diagrams for nickel-ferrite (left) and ceria (right) for a full cycle.

The heat losses through the insulation have a minor impact on the system performance. A larger energy amount (from $14.0 \%$ up to $22.7 \%$ ) is required for the heat-up of the working fluid entering the reactor.

As discussed above, a smart choice of the number of reactor in each module allows to dramatically reduce the non-used share of available solar power. Figure 7 shows the results of the optimization procedure. In both cases, the single reactors within one module are activated with such a time displacement that the peak power requirement of different reactors do not overlap. Then, the optimal number of modules per reactor is mainly a function of the duration of the heat-up phase. In principle, additional gains could be reached by the optimization of the heat-up profile. However, this would have been out of the scope of this preliminary work. In ceria both the temperature level of the TR phase as well as the spread between TR and WS temperature is higher than for nickel-ferrite. This leads to longer heat-up duration in ceria cycles. As a consequence, in ceria a lower number of reactors per module can be obtained than for nickel-ferrite. In the figure one can also observe that the cycle duration for nickel-ferrite is almost twice the cycle time for ceria. This is due to the different kinetics and temperature levels. In addition, the module peak power for ceria is roughly $40 \%$ higher than for nickel-ferrite.

The previous results show the behavior of single reactors and single modules under the assumption of constant available solar power. In reality, available sun power varies during the day and more than one module can be run at the same time, as shown in Figure 8.

For a given number of modules in a plant, only a certain fraction can be operated at the same time, depending of the currently available solar power. When the Sun power is equal or higher than the sum of the nominal power of a certain number of modules, such modules are heated up. Within each single module, the reactors are successively activated taking into account the time displacement between reactors. This module activation trend is visible in Figure 8, where during the morning hours 
the number of productive cycles is lower than the number of activated modules, since the heat-up procedure needs a certain time. Due to the fact that the cycle time in ceria is lower than in nickel-ferrite, ceria is more reactive than nickel-ferrite to variations in the available solar power.
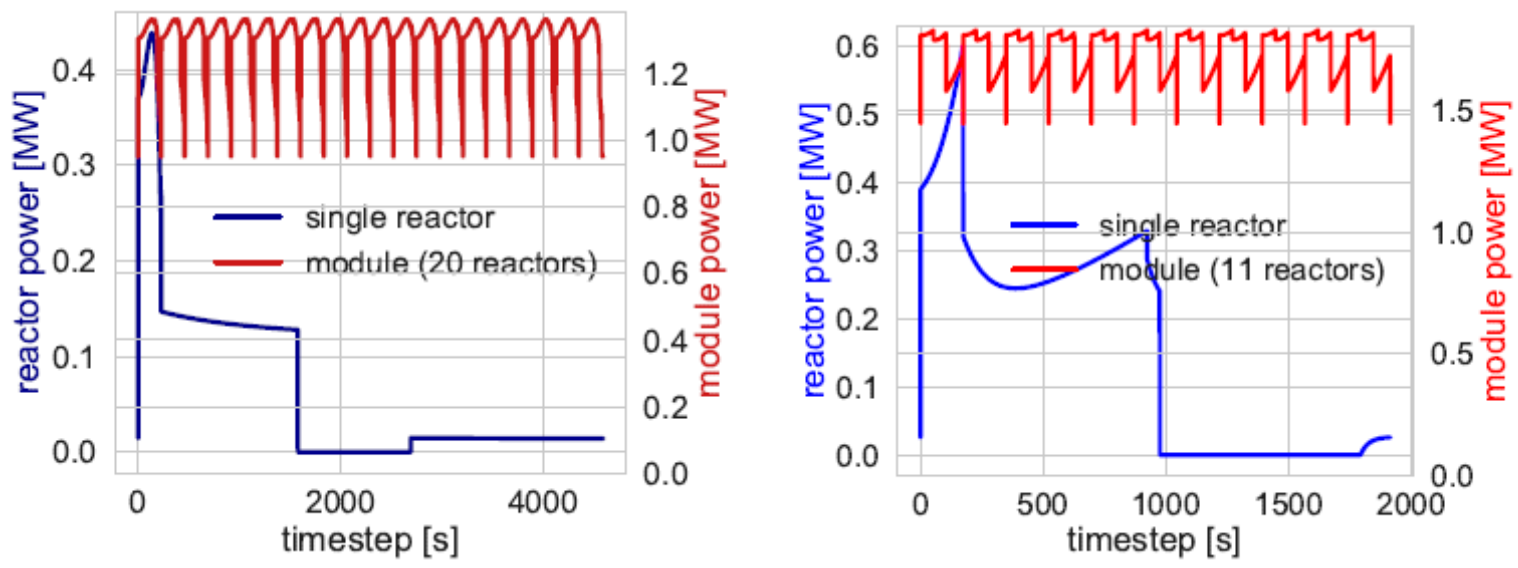

Figure 7. Solar power requirement for a single reactor and for a module (left: nickel-ferrite, right: ceria).

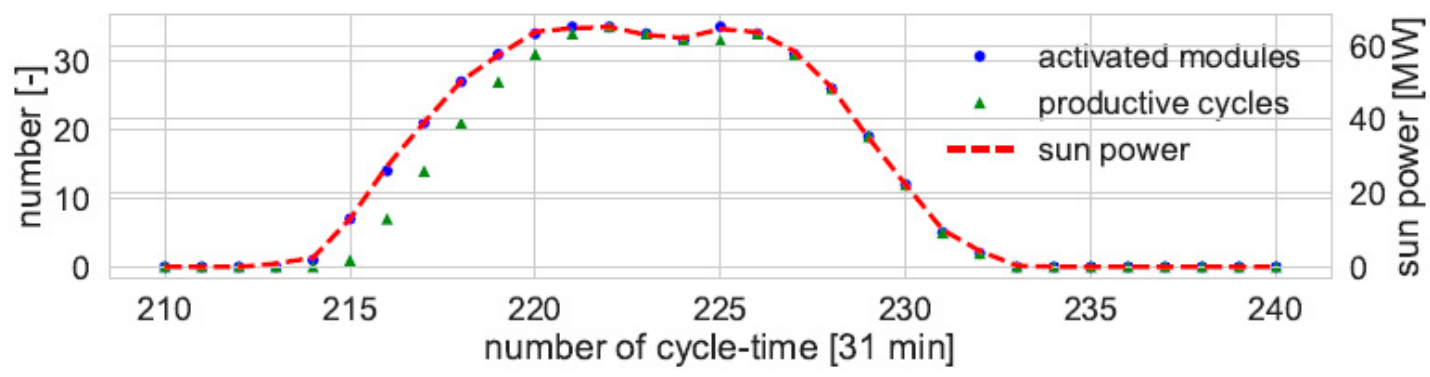

Figure 8. Plant daily performance (ceria, typical day, base case).

The total investment for the case is 35.5 Mio. $€$ for nickel-ferrite and 32.5 Mio. $€$ for ceria. The higher investment for nickel-ferrite is due to the higher number of reactors needed, which in turn is a result of the slower kinetics. However, since solar field investment (which is the same in both cases) accounts for ca. two thirds of the total investment, the difference is relatively small. The resulting $\mathrm{LCOH}$ are $38.83 € / \mathrm{kg}$ for nickel-ferrite and $13.06 € / \mathrm{kg}$ for ceria. Figure 9 shows the $\mathrm{LCOH}$ structure. In both cases, the instalment accounts for more than $60 \%$ of the $\mathrm{LCOH}$, while the substitution of the active material represents ca. another $20 \%$ of the specific production cost. The operation and maintenance cost amount to ca. $15 \%$ of $\mathrm{LCOH}$.
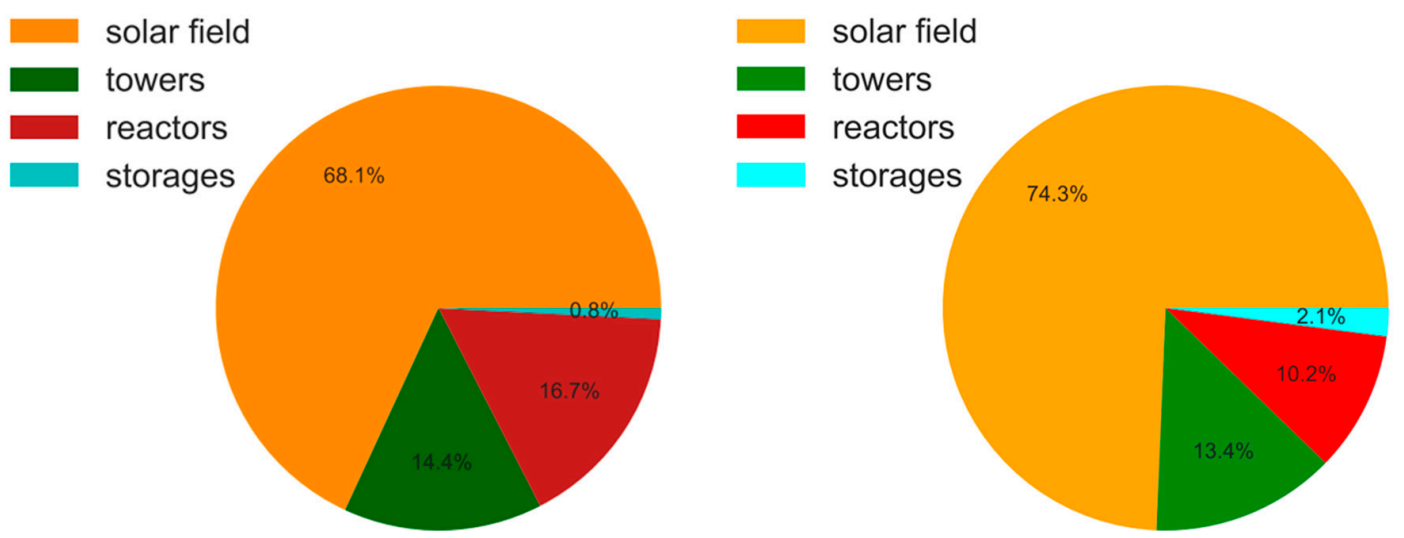

Figure 9. LCOH shares for the base case (left: nickel-ferrite, right: ceria). 
The conclusion is that solar field and tower cost are-less surprisingly-the most important cost factors. Also, the reduction of the substitution of metal oxide can significantly enhance the economic figures. Such considerations are confirmed by the sensitivity analysis for the case with ceria on economic parameters in Figure 10 (the case with nickel-ferrite is similar and it is reported in the Appendix A). The reduction of the cost of the solar field turns out to be by far the most important cost driver. In addition, absorber cost and life time play an important role. On the contrary, the impact of nitrogen cost or electricity cost for compressors on $\mathrm{LCOH}$ is almost negligible.

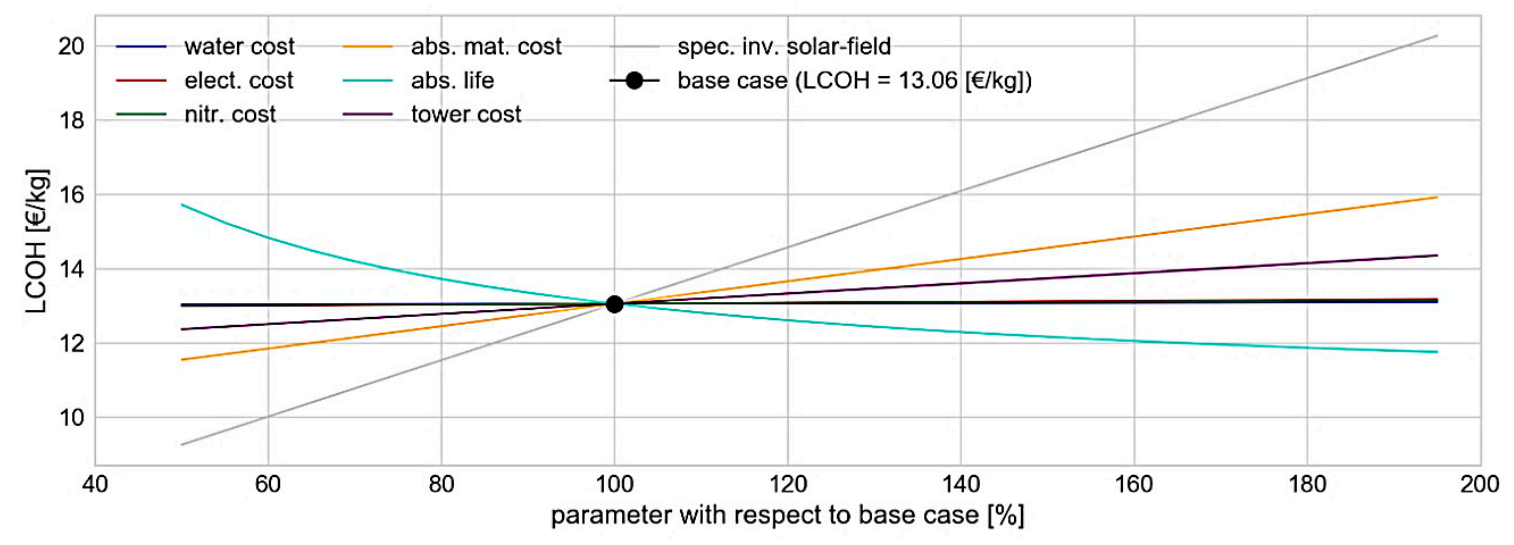

Figure 10. Sensitivity analysis of LCOH (ceria, base case).

Finally, a best case scenario for ceria has been evaluated. Nickel-ferrite has been neglected due to the higher $\mathrm{LCOH}$ in the base case. This scenario takes into account a reduction of the key economic parameters. In particular, heliostat field as well as tower cost are assumed to be reduced by $40 \%$. The active material cost is halved and the absorber life time has been extended from 1 year to 20 years. These assumptions, in particular those regarding the absorber life time, are very optimistic. However, this assumption is taken as this work aims at the evaluation of the long term potentials of this technology. The $\mathrm{LCOH}$ of ceria in the best case accounts to $6.68 € / \mathrm{kg}$. The results compare well with the figures recently presented by Nicodemus [25].

\section{Conclusions}

Within this paper a techno-economic model for the evaluation and comparison of different materials for solar thermochemical hydrogen production has been developed. The novelty of the model consists in the simplified but still flexible approach, which considers at the same time technical and economic aspects. In this way, the model is able to take into account the inter-dependence between economic input parameters and optimal plant design. In addition, the model makes possible evaluating key design and operation parameters of such plants, and comparing different materials (i.e., nickel-ferrite and ceria). Furthermore, sensitivity analyses over a wide range of techno-economic parameters can be easily realized.

The technical model has been developed based on available literature and in close collaboration with the DLR Institute of Solar Research. It consists of four sections including sun power evaluation, single reactor model, kinetics for both the considered materials, and complete plant model including underground hydrogen storage facilities. The model has been used to optimize the design of a large-scale solar hydrogen production plant (90 MWth solar reactor power at design). In particular, the design optimization procedure consists on the minimization of the solar power dumping which typically occurs due to the different heat requirements of the thermal reduction and water splitting phases, respectively. For both nickel-ferrite and ceria an optimal number of reactors per module has been found. Each of the reactors within one module is then operated with a suitable time displacement relative to the other reactors of the same module. The comparison demonstrated that ceria achieves higher efficiency than nickel-ferrite $(13.4 \%$ instead $6.4 \%)$, which is mainly due to the different kinetics. 
This difference leads to a lower LCOH for ceria $(13.06 € / \mathrm{kg}$ instead of $38.83 € / \mathrm{kg}$ for nickel-ferrite, both in the base case). The analysis of the cost structure highlighted the importance of reducing investment cost for solar field in order to improve the plant economics. A best case scenario with optimistic assumptions regarding investment cost and absorber life-time has been considered. LCOH in this case is $6.68 € / \mathrm{kg}$ for ceria. Finally, the integral evaluation of the thermal balances over a full cycles showed that around two third of the incoming solar radiation are lost due to re-radiation through the window. The main competitor of solar thermochemical cycles for hydrogen production remains photovoltaics-powered electrolysis, which is expected to reach specific production cost between $2 € / \mathrm{kg}$ and $3 € / \mathrm{kg}$ in the long term perspective.

Author Contributions: Conceptualization, M.M.; Formal analysis, M.M. and M.P.; Methodology, M.M., M.P. and T.F.; Software, M.P.; Supervision, M.M.; Writing—original draft, M.M.; Writing—review \& editing, M.M. and M.P.

Funding: This research was funded by the Helmholtz Association within the framework of the Program-Oriented Funding (DLR basic funding: "Future Fuels" Project).

Acknowledgments: A special thank goes to Matteo Pecchi for his extraordinary engagement during his stay at DLR.

Conflicts of Interest: The authors declare no conflict of interest. The funders had no role in the design of the study; in the collection, analyses, or interpretation of data; in the writing of the manuscript, or in the decision to publish the results.

\section{Abbreviations}

\begin{tabular}{|c|c|c|}
\hline \multicolumn{3}{|l|}{ Acronyms } \\
\hline COP & \multicolumn{2}{|c|}{ Conference of the Parties } \\
\hline CSP & \multicolumn{2}{|c|}{ Concentrating Solar Power } \\
\hline DLR & \multicolumn{2}{|c|}{ Deutsches Zentrum für Luft-und Raumfahrt (German Aerospace Center) } \\
\hline IEA & \multicolumn{2}{|c|}{ International Energy Agency } \\
\hline $\mathrm{MO}$ & \multicolumn{2}{|l|}{ Metal Oxide } \\
\hline O\&M & \multicolumn{2}{|c|}{ Operation and maintenance } \\
\hline PV & \multicolumn{2}{|c|}{ Photovoltaics } \\
\hline TR & \multicolumn{2}{|c|}{ Thermal Reduction Step } \\
\hline WS & \multicolumn{2}{|c|}{ Water Splitting Step } \\
\hline \multicolumn{3}{|l|}{ Symbols } \\
\hline$\dot{Q}_{h, \text { reac }}$ & [MWth] & Thermal power due to the chemical reactions \\
\hline$\dot{Q}_{a-f l, c o n v}$ & [MWth] & Convective power between absorber and working fluid \\
\hline$\dot{Q}_{a-i n s, \text { cond }}$ & [MWth] & Conductive power through the insulation \\
\hline$\dot{Q}_{a-w, r a d}$ & [MWth] & Radiation power emitted by the absorber toward the window \\
\hline$\dot{Q}_{a-w, \alpha}$ & [MWth] & Radiation power from absorber, absorbed by window \\
\hline$Q_{s f}$ & [MWth] & Solar field thermal power \\
\hline$\dot{Q}_{\text {sun }, \alpha}$ & [MWth] & Solar power absorbed \\
\hline$\dot{Q}_{\text {sun }, \tau}$ & [MWth] & Solar power transmitted by the absorber window \\
\hline$\dot{Q}_{w, \text { rad }}$ & [MWth] & Radiation power emitted by the window \\
\hline$\dot{Q}_{w-e n v, c o n v}$ & [MWth] & Convective power between window and environment \\
\hline$\dot{Q}_{w-f l, c o n v}$ & [MWth] & Convective power between window and working fluid \\
\hline$A_{s f}$ & {$\left[\mathrm{~m}^{2}\right]$} & Heliostat surface \\
\hline$T_{a}$ & {$[\mathrm{~K}]$} & Temperature of the absorber \\
\hline$T_{w}$ & {$[\mathrm{~K}]$} & Temperature of the window \\
\hline $\mathrm{LCOH}$ & {$[€ / \mathrm{kg}]$} & Levelized cost of hydrogen \\
\hline$c_{p, a b s}$ & {$[\mathrm{~kJ} / \mathrm{kg} / \mathrm{K}]$} & Specific heat of the absorber \\
\hline$c_{p, w}$ & {$[\mathrm{~kJ} / \mathrm{kg} / \mathrm{K}]$} & Specific heat capacity of the window \\
\hline$f_{\text {spill }}$ & {$[-]$} & Non-dimensional spillage factor \\
\hline$k_{\text {reg }}$ & {$\left[\mathrm{s}^{-1}\right]$} & Rate constant for regeneration step \\
\hline
\end{tabular}




$\begin{array}{lll}m_{a b s} & {[\mathrm{~kg}]} & \text { Absorber mass } \\ m_{w} & {[\mathrm{~kg}]} & \text { Windows mass } \\ \mathrm{t}_{\text {construction }} & {[\mathrm{y}]} & \text { Construction time } \\ \mathrm{t}_{\mathrm{debt}} & {[\mathrm{y}]} & \text { Debt period } \\ \eta_{s f} & {[-]} & \text { Solar field efficiency } \\ \psi_{\mathrm{O}_{2}} & {[\mathrm{~mol}]} & \text { Removable O2 at equilibrium } \\ \mathrm{DNI} & {\left[\mathrm{W} / \mathrm{m}^{2}\right]} & \text { Direct Normal Irradiance } \\ d t & {[\mathrm{~s}]} & \text { Time step } \\ \mathrm{i} & {[\% / \mathrm{y}]} & \text { Interest rate } \\ \text { inv } & {[\text { Mio. } €]} & \text { Total investment }\end{array}$

Appendix A

Table A1. Demonstrations of solar thermochemical hydrogen production (adapted from [17]).

\begin{tabular}{llll}
\hline Parameter & Non-volatile Metal Oxide & Volatile Metal & Sulfur-Based \\
\hline Project & HYDROSOL-Plant [20] & $\begin{array}{l}\text { Solar production of zinc } \\
\text { and hydrogen [38] }\end{array}$ & SOL2HY2 [39] \\
\hline Years & $2014-2017$ & $2008-2015$ & $2013-2016$ \\
\hline Location & PSA, Spain & Odeillo, France & Jülich, Germany \\
\hline Cycle Type & Doped ferrites & Zinc oxide & Modified hybrid sulfur \\
\hline Reactor Type & Stationary monolithic honeycomb with & $\begin{array}{l}\text { Windowed cavity with } \\
\text { oxide particles }\end{array}$ & $\begin{array}{l}\text { Stationary catalyst coated monolithic absorber with } \\
\mathrm{CPC} \text { and quartz glass window }\end{array}$ \\
\hline Scale & CPC and quartz glass window & $100 \mathrm{~kW}_{\text {th }}$ & $100 \mathrm{~kW}$ th \\
\hline Max. Temp. & $750 \mathrm{~kW}_{\text {th }}$ & $1750^{\circ} \mathrm{C}$ & $1200^{\circ} \mathrm{C}$ \\
\hline Challenges & $1400{ }^{\circ} \mathrm{C}$ & Low heat-up & Windows scale-up \\
\hline
\end{tabular}

Table A2. Structure of the heliostat field efficiency matrix, as a function of solar elevation angle (vertical axis) and solar azimuth angle (horizontal axis)-example for intercept power 11.5 MWth and latitude $20^{\circ} \mathrm{N}$.

\begin{tabular}{lccccccccccccc}
\hline $\begin{array}{l}\text { Azimuth } \rightarrow \\
\text { Sun height } \downarrow\end{array}$ & $\mathbf{0}^{\circ}$ & $\mathbf{1 5}^{\circ}$ & $\mathbf{3 0}^{\circ}$ & $\mathbf{4 5}^{\circ}$ & $\mathbf{6 0}^{\circ}$ & $\mathbf{7 5}^{\circ}$ & $\mathbf{9 0}^{\circ}$ & $\mathbf{1 0 5}^{\circ}$ & $\mathbf{1 2 0}^{\circ}$ & $\mathbf{1 3 5}^{\circ}$ & $\mathbf{1 5 0}^{\circ}$ & $\mathbf{1 6 5}^{\circ}$ & $\mathbf{1 8 0}^{\circ}$ \\
\hline $\mathbf{0}^{\circ}$ & 0 & 0 & 0 & 0 & 0 & 0 & 0 & 0 & 0 & 0 & 0 & 0 & 0 \\
$\mathbf{1 . 2}^{\circ}$ & 0.0913 & 0.0941 & 0.0909 & 0.0966 & 0.0999 & 0.1027 & 0.1112 & 0.123 & 0.1303 & 0.1389 & 0.1413 & 0.1459 & 0.143 \\
$\mathbf{5 . 2}^{\circ}$ & 0.1417 & 0.1458 & 0.1446 & 0.1549 & 0.1621 & 0.1715 & 0.1815 & 0.2005 & 0.2106 & 0.2233 & 0.2269 & 0.2356 & 0.2307 \\
$\mathbf{1 5}^{\circ}$ & 0.2883 & 0.2951 & 0.2988 & 0.3185 & 0.3318 & 0.3558 & 0.3687 & 0.4036 & 0.423 & 0.4479 & 0.4577 & 0.4743 & 0.4623 \\
$\mathbf{2 4 . 9}^{\circ}$ & 0.4072 & 0.4121 & 0.4166 & 0.4389 & 0.464 & 0.4864 & 0.4972 & 0.5414 & 0.5711 & 0.5919 & 0.6059 & 0.6255 & 0.6241 \\
$\mathbf{3 4 . 8}^{\circ}$ & 0.4877 & 0.4904 & 0.4943 & 0.5166 & 0.5441 & 0.5621 & 0.5823 & 0.6152 & 0.6471 & 0.6636 & 0.6762 & 0.6949 & 0.7003 \\
$\mathbf{4 4 . 6}^{\circ}$ & 0.5511 & 0.5473 & 0.5499 & 0.5706 & 0.5957 & 0.6112 & 0.6284 & 0.6587 & 0.688 & 0.7021 & 0.7123 & 0.7297 & 0.7405 \\
$\mathbf{5 9 . 4}^{\circ}$ & 0.6348 & 0.6367 & 0.637 & 0.6538 & 0.6676 & 0.6841 & 0.6956 & 0.7202 & 0.7374 & 0.7529 & 0.759 & 0.7733 & 0.7765 \\
$\mathbf{7 5 . 2}^{\circ}$ & 0.7138 & 0.7149 & 0.7184 & 0.7239 & 0.7312 & 0.7399 & 0.7494 & 0.7591 & 0.7684 & 0.7766 & 0.7829 & 0.787 & 0.7885 \\
$\mathbf{9 0}^{\circ}$ & 0.7695 & 0.7695 & 0.7695 & 0.7695 & 0.7695 & 0.7695 & 0.7695 & 0.7695 & 0.7695 & 0.7695 & 0.7695 & 0.7695 & 0.7695 \\
\hline
\end{tabular}

Table A3. List of ranges used for the economic parametric study.

\begin{tabular}{lcccc}
\hline Parameter & Unit & Base Case & Min & Max \\
\hline Water cost & $€ / \mathrm{m}^{3}$ & 3 & 1.5 & 6 \\
Electricity cost & $€ / \mathrm{kWh}$ & 0.20 & 0.10 & 0.40 \\
Absorber life time & $\mathrm{y}$ & 1 & 0.5 & 2 \\
Absorber specific cost & $€ / \mathrm{kg}$ & 10 & 5 & 20 \\
$\mathrm{~N}_{2}$ electricity consumption & $\mathrm{kWh} / \mathrm{mol}$ & 0.001356 & 0.000678 & 0.002712 \\
Tower cost factor & $\%$ & 100 & 50 & 200 \\
Solar field specific investment & $€ / \mathrm{m}^{2}$ & 150 & 75 & 300 \\
\hline
\end{tabular}




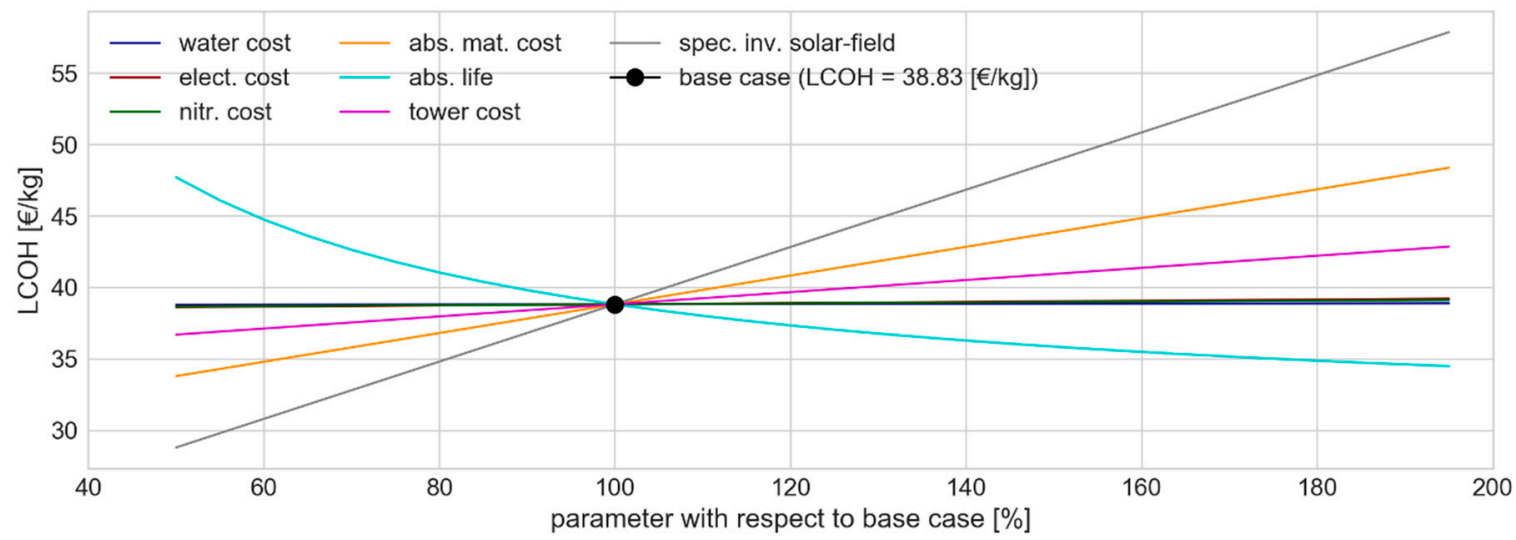

Figure A1. Sensitivity analysis of LHC (nickel-Ferrite, base case).

\section{References}

1. International Energy Agency (IEA). World Energy Outlook 2015. Available online: www.iea.org/ publications/freepublications/publication/WEO2015.pdf (accessed on 11 November 2017).

2. British Petroleum (BP). BP Global. BP Energy Outlook 2017 Edition. Available online: https://www.bp.com/ en/global/corporate/energy-economics/energy-outlook/energy-outlook-downloads.html (accessed on 22 January 2019).

3. Wang, F.-C.; Hsiao, Y.-S.; Yang, Y.-Z. The Optimization of Hybrid Power Systems with Renewable Energy and Hydrogen Generation. Energies 2018, 11, 1948. [CrossRef]

4. SolarPACES-Solar Power and Chemical Energy Systems Implementing Agreement of the International Energy Agency. Solar Fuels from Concentrated Sunlight. 2010 Report. Available online: stage-ste.eu (accessed on 22 January 2019).

5. Bozoglan, E.; Midilli, A.; Hepbasli, A. Sustainable assessment of solar hydrogen production techniques. Energy 2012, 46, 85-93. [CrossRef]

6. Kalogirou, S.A. Chapter 9. In Photovoltaic Systems, Solar Energy Engineering, 2nd ed.; Processes and Systems; Academic Press: Cambridge, MA, USA, 2014; pp. 481-540. [CrossRef]

7. Kovač, A.; Marciuš, D.; Budin, L. Solar hydrogen production via alkaline water electrolysis. Int. J. Hydrogen Energy 2018. [CrossRef]

8. Baykara, S.Z. Experimental solar water thermolysis. Int. J. Hydrogen Energy 2004, 29, 1459-1469. [CrossRef]

9. Ihara, S. Direct Thermal Decomposition of Water; Ohta, T., Ed.; Solar energy systems, Pergamon Press: New York, NY, USA, 1989; pp. 59-79.

10. Kogan, A. Direct solar thermal splitting of water and on site separation of the products-Theoretical evaluation of the hydrogen yield. Int. J. Hydrogen Energy 1997, 22, 481-486. [CrossRef]

11. Tyner, C.E.; Kolb, G.J.; Meinecke, W.; Trieb, F. Concentrating Solar Power in 1999-An IEA/SolarPACES Summary of Status and Future Prospects. SolarPACES 1999, 9. [CrossRef]

12. Kaleibari, S.; Yanping, Z.; Abanades, S. Solar-driven high temperature hydrogen production via integrated spectrally split concentrated photovoltaics (SSCPV) and solar power tower. Int. J. Hydrogen Energy 2018. [CrossRef]

13. Agrafiotis, C.; Roeb, M.; Sattler, C. A review on solar thermal syngas production via redox pair-based water/carbon dioxide splitting thermochemical cycles. Renew. Sustain. Energy Rev. 2015, 42, 254-285. [CrossRef]

14. Villafán-Vidales, H.I.; Arancibia-Bulnes, C.A.; Riveros-Rosas, D.; Romero-Paredes, H.; Estrada, C.A. An overview of the solar thermochemical processes for hydrogen and syngas production: Reactors, and facilities. Renew. Sustain. Energy Rev. 2017, 75, 894-908. [CrossRef]

15. Miller, J.E.; Allendorf, M.D.; Diver, R.B.; Evans, L.R.; Siegel, N.P.; Stuecker, J.N. Metal oxide composites and structures for ultra-high temperature solar thermochemical cycles. J. Mater. Sci. 2008, 43, 4714-4728. [CrossRef] 
16. Bhosale, R.; Kumar, A.; AlMomani, F.; Ghosh, U.; Saad Anis, M.; Kakosimos, K.; Shende, R.; Rosen, M.A. Solar Hydrogen Production via a Samarium Oxide-Based Thermochemical Water Splitting Cycle. Energies 2016, 9, 316. [CrossRef]

17. Hinkley, J.; Agrafiotis, C. Solar Thermal Energy and its Conversion to Solar Fuels via Thermochemical Processes, Polygeneration with Polystorage for Chemical and Energy Hubs; Academic Press: Cambridge, MA, USA, 2019; pp. 247-286. [CrossRef]

18. Steinfeld, A. Solar thermochemical production of hydrogen-A review. Sol. Energy 2005, 78, $603-615$. [CrossRef]

19. Lange, M. Efficiency Analysis of Solar Driven Two-Step Thermochemical Water Splitting Processes Based on Metal Oxide Redox Pairs. Ph.D. Thesis, RWTH Aachen University, Aachen, Germany, 2014; p. 153. Available online: http:/ / publications.rwth-aachen.de/record/444960 (accessed on 22 January 2019).

20. Säck, J.P.; Breuer, S.; Cotelli, P.; Houaijia, A.; Lange, M.; Wullenkord, M.; Spenke, C.; Roeb, M.; Sattler, C. High temperature hydrogen production: Design of a $750 \mathrm{KW}$ demonstration plant for a two-step thermochemical cycle. Sol. Energy 2016, 135, 232-241. [CrossRef]

21. Furler, P.; Scheffe, J.; Steinfeld, A. Syngas production by simultaneous splitting of water and carbon dioxide via ceria redox reactions in a high temperature solar reactor. Energy Environ. Sci. 2012, 5, 6098-6103. [CrossRef]

22. Marxer, D.; Furler, P.; Scheffe, J.; Geerlings, H.; Falter, C.; Batteiger, V.; Sizmann, A.; Steinfeld, A. Demonstration of the entire production chain to renewable kerosene via solar thermochemical splitting of $\mathrm{H}_{2} \mathrm{O}$ and $\mathrm{CO}_{2}$. Energy Fuel 2015, 29, 3241-3250. [CrossRef]

23. Marxer, D.; Furler, P.; Takacs, M.; Steinfeld, A. Solar thermochemical splitting of $\mathrm{CO}_{2}$ into separate streams of $\mathrm{CO}$ and $\mathrm{O}_{2}$ with high selectivity, stability, conversion, and efficiency. Energy Environ. Sci. 2017, 10, 1142-1149. [CrossRef]

24. Graf, D.; Monnerie, N.; Roeb, M.; Schmitz, M.; Sattler, C. Economic comparison of solar hydrogen generation by means of thermochemical cycles and electrolysis. Int. J. Hydrogen Energy 2008, 33, 4511-4519. [CrossRef]

25. Nicodemus, J.H. Technological learning and the future of solar $\mathrm{H}_{2}$ : A component learning comparison of solar thermochemical cycles and electrolysis with solar PV. Energy Policy 2018, 120, 100-109. [CrossRef]

26. Schenk, H. ENERMENA-Yield Analysis for Parabolic trough Solar Thermal Power Plants; Internal Report; Deutsches Zentrum für Luft und Raumfahrt (DLR): Köln, Germany, 2011.

27. Dersch, J.; Schwarzbözl, P.; Richert, T. Annual Yield Analysis of Solar Tower Power Plants with GREENIUS. J. Sol. Energy Eng. 2011, 133. [CrossRef]

28. Pecchi, M. System Analysis of Solar Hydrogen Production-Mathematical Modelling and Techno-Economic Assessment. Master's Thesis, Germany and University of Trento, Trento, Italy, 2017.

29. Garcia, L.; Burisch, M.; Sanchez, M. Spillage estimation in a heliostats field for solar field optimization. Energy Procedia 2015, 69, 1269-1276. [CrossRef]

30. Agrafiotis, C.; Zygogianni, A.; Pagkoura, C.; Kostoglou, M.; Konstandopoulos, A.G. Hydrogen production via solar-aided water splitting thermochemical cycles with nickel ferrite: Experiments and modelling. AIChE J. 2013, 59, 1213-1225. [CrossRef]

31. Diver, R.B.; Miller, J.E.; Allendorf, M.D.; Siegel, N.P.; Hogan, R.E. Solar Thermochemical Water-Splitting Ferrite-Cycle Heat Engines. J. Sol. Energy Eng. 2008, 130, 041001. [CrossRef]

32. Nelson, A.T.; White, J.T.; Andersson, D.A.; Aguiar, J.A.; McClellan, K.J.; Byler, D.D.; Short, M.P.; Stanek, C.R. Thermal Expansion, Heat Capacity, and Thermal Conductivity of Nickel Ferrite $\left(\mathrm{NiFe}_{2} \mathrm{O}_{4}\right)$. J. Am. Ceram. Soc. 2014, 97, 1559-1565. [CrossRef]

33. Furler, P. Solar Thermochemical $\mathrm{CO}_{2}$ and $\mathrm{H}_{2} \mathrm{O}$ Splitting via Ceria Redox Reactions. Ph.D. Thesis, ETH, Zurich, Switzerland, 2014.

34. Chueh, W.C.; Haile, S.M. A thermochemical study of ceria: Exploiting an old material for new modes of energy conversion and $\mathrm{CO}_{2}$ mitigation. Philos. Trans. R. Soc. Lond. A Math. Phys. Eng. Sci. 2010, 368, 3269-3294. [CrossRef]

35. Parks, G.; Boyd, R.; Cornish, J.; Remick, R. Hydrogen Station Compression, Storage, and Dispensing Technical Status and Costs; NREL Technical Report NREL/BK-6A10-58564; NREL: Golden, CO, USA, 2014. Available online: www.nrel.gov (accessed on 22 January 2019). 
36. Nitsch, J.; Pregger, T.; Naegler, T.; Heide, D.; de Tena, D.L.; Trieb, F.; Scholz, Y.; Nienhaus, K.; Gerhardt, N.; Sterner, M.; et al. Langfristszenarien und Strategien für den Ausbau der Erneuerbaren Energien in Deutschland bei Berücksichtigung der Entwicklung in Europa und Global; Report for the German Ministry of Environment; DLR, IWES, IFNE: Stuttgart, Germany, 2011. (In German)

37. Solargis-Weather Data and Software for Solar Power Investments. Available online: https://solargis.com/ (accessed on 19 December 2018).

38. Villasmil, W.; Brkic, M.; Wuillemin, D.; Meier, A.; Steinfeld, A. Pilot scale demonstration of a 100-kWth solar thermochemical plant for the thermal dissociation of ZnO. J. Sol. Energy Eng. 2013, 136, 011016. [CrossRef]

39. Odorizzi, S. ENGINSOFT S. SOL2HY2-Solar to Hydrogen Hybrid Cycles Project Publishable Summary. 2016. Available online: http://cordis.europa.eu/docs/results/325/325320/final1-sol2hy2-publishablesummary-final-report-24-2.pdf (accessed on 22 January 2019).

(C) 2019 by the authors. Licensee MDPI, Basel, Switzerland. This article is an open access article distributed under the terms and conditions of the Creative Commons Attribution (CC BY) license (http://creativecommons.org/licenses/by/4.0/). 